\title{
Acyclovir vs isoprinosine (immunovir) for suppression of recurrent genital herpes simplex infection
}

\author{
G R Kinghorn, P D Woolley, R N T Thin, J De Maubeuge, J M Foidart, R Engst
}

\begin{abstract}
Objective-To compare the efficacy and safety of oral acyclovir $(400 \mathrm{mg}$ twice daily) with oral isoprinosine $(500 \mathrm{mg}$ twice daily) in the suppression of recurrent genital herpes.

Design-Double-blind, double-dummy, randomised, controlled, parallel group trial.

Setting-13 centres in UK, Belgium and Germany.

Subjects-127 immunocompetent patients with frequently recurring genital herpes. Main outcome measures-Proportions of patients reporting recurrences, recurrence frequency, and mean duration of lesions during breakthrough recurrences in each treatment group during a 6 month treatment period; time to first recurrence during treatment and follow-up after treatment cessation.
\end{abstract}

Results-During treatment, acyclovir recipients showed significant differences $(p<0.05)$ when compared with isoprinosine recipients in terms of a lower proportion reporting recurrences (31\% vs $96 \%$ ), a reduced mean number of reported recurrences per patient $(0.6$ vs 3.6$)$, a shorter mean duration of breakthrough lesions (6.4 days vs $8 \cdot 2$ days), and a longer mean time (standard error) to first recurrence $(143.7(9.1)$ days vs $40.5(5.4)$ days. The mean time to first recurrence after treatment cessation did not differ between the two groups. As compared with placebo recipients, isoprinosine treated patients had an increased recurrence frequency (3.6 vs 2.5$)$ during treatment, and a shorter time to first recurrence after treatment cessation. All treatments were well tolerated without serious adverse events or toxicity.

Conclusions-Acyclovir is very effective in suppressing recurrent genital herpes and is clearly superior to isoprinosine which is not clinically useful in the dosage studied.

\section{Introduction}

Recurrent genital herpes (RGH) infections are becoming increasingly common and are often a source of considerable physical discomfort and emotional disturbance in affected patients. Numerous different treatments have been suggested for the management of patients with genital herpes; these include antiviral drugs and immuno-modulators. ${ }^{12}$ The majority of these preparations have been shown in clinical trials to be ineffective. However, both acyclovir and inosine pranobex/isoprinosine have been reported to reduce the frequency of recurrences in separate controlled trials. ${ }^{3-11}$

The aim of this study was to compare the efficacy and tolerance of these oral agents in the suppression of RGH infections in comparison with placebo.

\section{Patients and methods}

Study design

This was a multi-centre, double-blind, doubledummy, randomised, controlled, parallel group trial in patients with a history of $\mathrm{RGH}$. The study was approved by the Ethical Committee of each hospital prior to patient entry.

\section{Patient selection and exclusion}

Patients aged 16 years or more with a known history of frequent attacks of recurrent herpes genitalis (six or more per year) were invited to participate. A culture positive recurrence during the observation period was necessary for inclusion in the study. Women who were not adequately protected against pregnancy, and patients of either sex with known HIV infection, other causes of immunosuppression, a history of gastrointestinal malabsorption, renal disease with a creatinine clearance below $50 \mathrm{ml} / \mathrm{min}$, gout or hyperuricaemia, or severe atopic eczema were excluded. All patients were informed of the experimental nature of the treatment and were asked to give their consent to participate, prior to entering the study.

\section{Patient management}

Eligible patients were initially observed without treatment for 8 weeks. During this observation period, they were required to complete daily diary cards detailing symptoms and signs of recurrences. They were asked to return to the clinic either at the first signs of a subsequent recurrence, when separate swabs were taken from external and internal lesions present, or otherwise every 4 weeks when diary cards were checked and replaced.

They then progressed to the treatment period which continued for 24 weeks. Treatment was commenced 7 days after the start of the first recurrence subsequent to the observation period. Each patient was given two bottles of tablets and instructed to take one tablet from each twice daily. They were randomly assigned to treatment with one of the following:
Address correspondence to: Dr G R Kinghorn

Accepted for publication 19 May 1992 
Table 1 Demographic data at study entry

\begin{tabular}{|c|c|c|c|}
\hline & $\begin{array}{l}\text { Placebo } \\
(N=25)\end{array}$ & $\begin{array}{l}\text { Acyclovir } \\
(N=53)\end{array}$ & $\begin{array}{l}\text { Isoprinosine } \\
(N=49)\end{array}$ \\
\hline $\begin{array}{l}\text { Males (\%) } \\
\text { Females (\%) } \\
\text { Age (Mean years, SD) } \\
\text { History of genital herpes, no episodes preceding year }\end{array}$ & $\begin{array}{l}60 \\
40 \\
33 \cdot 7,10 \cdot 9\end{array}$ & $\begin{array}{l}69 \\
31 \\
33 \cdot 5,8 \cdot 3\end{array}$ & $\begin{array}{l}59 \\
41 \\
35 \cdot 7,10 \cdot 4\end{array}$ \\
\hline $\begin{array}{l}\text { (Mean, SD) } \\
\text { Average Duration (Mean days, SD) } \\
\text { Symptom Severity (Mean score) }\end{array}$ & $\begin{array}{cc}11 \cdot 7, & 7 \cdot 3 \\
9 \cdot 2, & 2 \cdot 7 \\
1 \cdot 8 & \end{array}$ & $\begin{array}{l}10 \cdot 9,5 \cdot 0 \\
8 \cdot 6,3 \cdot 6 \\
1 \cdot 8\end{array}$ & $\begin{array}{cc}10 \cdot 8, & 6 \cdot 4 \\
8 \cdot 7, & 3 \cdot 9 \\
2 \cdot 0 & \end{array}$ \\
\hline
\end{tabular}

(1) active acyclovir ${ }^{\star}$ (400 $\mathrm{mg}$ twice daily) and isoprinosine placebo; (2) active isoprinosinet (500 mg twice daily) and acyclovir placebo; (3) both isoprinosine placebo and acyclovir placebo.

The protocoled ratio of patients assigned to the acyclovir, isoprinosine, and placebo treatment groups were 2:2:1 respectively. The code for allocating patients to each of the treatment groups was prepared using a computer generated randomisation table by the Department of Clinical Statistics and Data Handling, Wellcome Research Laboratories, Beckenham, Kent.

Patients were followed-up for a further 24 weeks after cessation of treatment ("follow up period") to assess their post-treatment recurrence pattern. The first two recurrences were not treated, thereafter the patients were issued with acyclovir cream.

\section{Measurements and evaluations}

Throughout treatment and subsequent follow up, patients reported compliance and symptoms on diary cards. They were observed monthly and during recurrences of infection for clinical and safety assessments. Whenever possible, the patient suspicion of recurrence was clinically confirmed. Concomitant medication was not restricted, but was recorded in each patient's case record form.

Blood samples were taken for routine haematological and biochemical measurements immediately before treatment started, once every eight weeks during the treatment period, and at the first visit after treatment was discontinued. Haematological parameters measured included haemoglobin, haematocrit, red blood cell count, white blood cell count, neutrophil, lymphocyte and platelet counts. Biochemical parameters measured included serum creatinine concentration, urea and uric acid concentrations and aspartate transaminase as an indicator of liver function.

All adverse events were recorded and rated by the investigator for severity and for the possibility of an association with the study drug(s) at each visit.

\section{Data analysis}

For all analyses, the data were pooled over centres because of the low patient numbers in some centres.

Summary statistics to describe the age, sex,

*Acyclovir tablets $(400 \mathrm{mg}$ ) with matching placebo were made, packed and labelled by the Wellcome Foundation Limited at Dartford, UK.

†Isoprinosine tablets $(500 \mathrm{mg}$ ) were obtained from a wholesaler. The tablets were made, packed and labelled by Edwin Burgess Limited, Aylesbury, UK. Matching inerts were made by the Wellcome Foundation at Dartford, UK. number and severity of HSV episodes were calculated for the patients in each of the three treatment groups. The efficacy and laboratory data were dual entered and edited into a computer database system for analysis. All the summary statistics were produced using the SAS statistical package. The Kaplan-Meier curves were calculated using the SAS procedure PROC LIFETEST.

\section{Results \\ Number of patients}

A total of 127 patients were entered into the study. Ten patients did not experience a recurrence during the observation period. One withdrew from the study and nine continued in the treatment and follow up periods. Of these five received acyclovir, two received isoprinosine and two received placebo. Thus, a total of 126 patients were included for the efficacy analysis.

Demographic details and baseline characteristics Demographic details and baseline characteristics of patients at entry are summarised in table 1. The three treatment groups were comparable for mean age, sex ratio, and preceding history of recurrent genital herpes.

Number of patients reporting recurrent lesions (table 2)

During two months observation, the percentages of patients reporting one or more recurrences were $91 \%$ in the acyclovir group, $96 \%$ in the isoprinosine group and $92 \%$ in the placebo group. During the 6 month treatment period, however, the percentage of patients reporting one or more recurrences was $31 \%$ in the acyclovir group, $96 \%$ in the isoprinosine group and $79 \%$ in the placebo group. The percentage of patients in the acyclovir group was significantly lower $(p<0.05)$ than the percentages in either the placebo group or the isoprinosine group.

During follow up, the percentage of patients reporting one or more recurrences was $82 \%$ in the acyclovir group, $69 \%$ in the isoprinosine group and $50 \%$ in the placebo group. The difference between the percentages in the acyclovir and isoprinosine groups were not statistically significant, however there were significantly fewer recurrences amongst placebo treated patients $(\mathrm{p}<0.05)$.

\section{Number of reported recurrent episodes}

The mean number of reported recurrent infections per patient during the 2 months observation period was similar in all three treatment groups (table 2).

During treatment, the mean number of reported recurrences per patient was 0.6 in the acyclovir group, 3.6 in the isoprinosine group and 2.5 in the placebo group. These mean values were significantly different $(p<0.05)$ between all pairs of treatments. In the acyclovir group only $3.6 \%$ of patients had three or more reported recurrences compared with $59.2 \%$ in the isoprinosine group and $41.7 \%$ in the placebo group. 
Table 2 Frequency of recurrences

\begin{tabular}{|c|c|c|c|c|c|c|}
\hline & \multicolumn{3}{|l|}{ Treatment group } & \multicolumn{3}{|c|}{$95 \%$ confidence intervals for differences } \\
\hline & Placebo $(N=24)$ & Acyclovir $(N=53)$ & Isoprinosine $(N=49)$ & $A-P$ & $I-P$ & $A-I$ \\
\hline $\begin{array}{l}\text { No. (\%) patients reporting } \\
\text { Observation } \\
\text { Treatment } \\
\text { Follow-up }\end{array}$ & $\begin{array}{c}g \text { a recurrence } \\
22.0(92 \%) \\
19.0(79 \%) \\
12.0(50 \%)\end{array}$ & $\begin{array}{l}50.0(91 \%) \\
17.0(31 \%) \\
45.0(82 \%)\end{array}$ & $\begin{array}{l}47.0(96 \%) \\
47.0(96 \%) \\
34.0(69 \%)\end{array}$ & 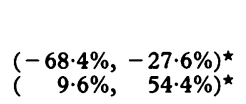 & $\begin{array}{c}(1 \cdot 9 \%, 34 \cdot 2 \%) \\
(-4 \cdot 8 \%, 42 \cdot 8 \%)^{\star}\end{array}$ & $\begin{array}{l}(-78.4 \%,-51 \cdot 6 \%)^{\star} \\
(-3.5 \%, \quad 29.5 \%)\end{array}$ \\
\hline $\begin{array}{l}\text { Mean no. recurrences per } p \\
\text { Observation } \\
\text { Treatment } \\
\text { Follow-up }\end{array}$ & $\begin{array}{r}\text { patients } \\
2 \cdot 13 \\
2.54 \\
1.67\end{array}$ & $\begin{array}{l}2 \cdot 29 \\
0 \cdot 64 \\
2 \cdot 82\end{array}$ & $\begin{array}{l}2 \cdot 76 \\
3 \cdot 57 \\
2 \cdot 92\end{array}$ & $\begin{array}{l}(-2.90,-0.91)^{\star} \\
(-0.11, \quad 2.41)\end{array}$ & $\begin{array}{l}\left(\begin{array}{c}0.01,2.04 \\
(-0.04,2.53)\end{array}\right.\end{array}$ & $\begin{array}{l}(-3.73,-2.14)^{\star} \\
(-1.11,0.92)\end{array}$ \\
\hline $\begin{array}{l}\text { Mean time (days) to first } \\
\text { Treatment } \\
\text { Follow-up } \neq \\
\text { Treatment to study end }\end{array}$ & $\begin{array}{l}\text { recurrence } \\
56 \cdot 2(10.9) \\
244.7(10.6) \\
88.1(22 \cdot 6)\end{array}$ & $\begin{array}{l}143 \cdot 7(9 \cdot 1) \\
239 \cdot 5(8 \cdot 0) \\
188 \cdot 2(14 \cdot 3)\end{array}$ & $\begin{array}{r}40.5(5.4) \\
240.4(9.8) \\
40.5(5.4)\end{array}$ & $\begin{array}{l}(59 \cdot 7,115 \cdot 2)^{\star} \\
(-31 \cdot 3,20 \cdot 8) \\
(47 \cdot 7,152 \cdot 5)^{\star}\end{array}$ & 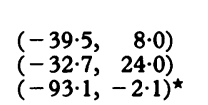 & $\begin{array}{l}(82 \cdot 5,123 \cdot 9)^{\star} \\
(-25 \cdot 7,23 \cdot 9) \\
(117 \cdot 7,177 \cdot 6)^{\star}\end{array}$ \\
\hline
\end{tabular}

^Significant at $5 \%$ level.

†To first recurrence during treatment.

To first recurrence in follow-up (from start of treatment period).

ҒTo first recurrence in follow-up (from start of treatment period)
\$To first recurrence at any time during treatment or follow-up.

Table 3 Duration of recurrences and symptoms

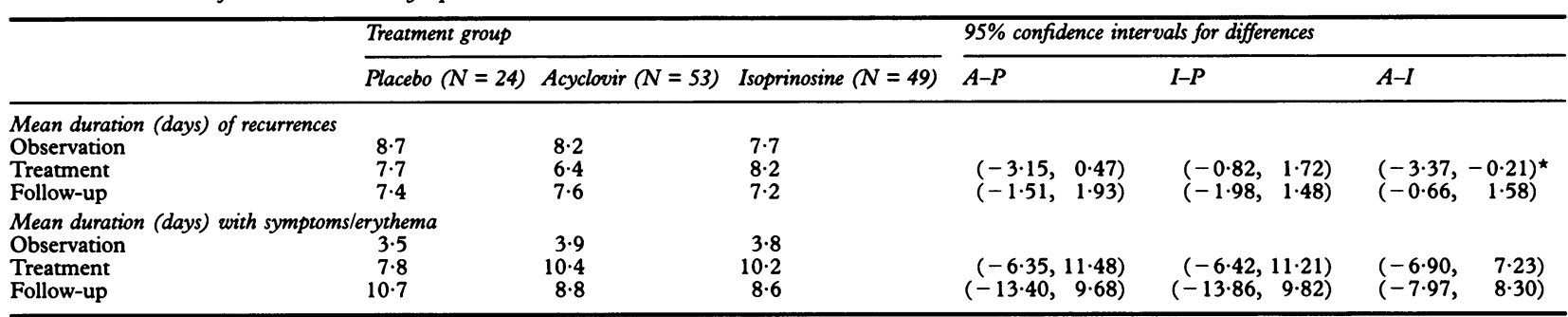

^Significant at $5 \%$ level.

During follow up, the mean number of reported recurrences per patient was 2.8 in the acyclovir group, 2.9 in the isoprinosine group and 1.7 in the placebo group. There were no statistically significant differences between any pairs of treatment groups.

\section{Number of days from treatment onset to first recurrence}

The mean time to the first recurrence from the start of treatment was estimated for each treatment group. This was significantly longer $(p<0.05)$ for acyclovir recipients $(143.7$ days), than for isoprinosine recipients $(40 \cdot 5$ days) or for placebo recipients (56.2 days) (table 2). The mean time to the first recurrence in the post-treatment period, measured from the start of the treatment period was virtually the same in all three treatment groups.

The distributions of the Kaplan-Meier estimates of proportions of recurrence-free patients showed there were significant differ-

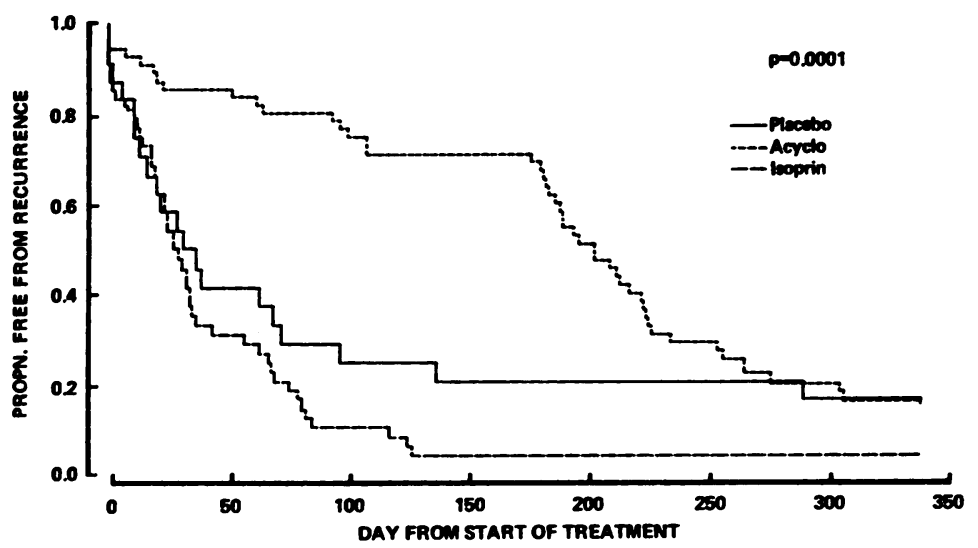

Figure 1 Time to 1st recurrent episode during treatment and follow-up for all patients in study. ences between the acyclovir and placebo groups $(p=0.0001)$ and between the acyclovir and isoprinosine groups ( $p=0.0001$ ) (fig 1 ). There was no significant difference between the placebo and isoprinosine groups. During follow up, there was no statistical evidence to suggest that the distributions of Kaplan-Meier estimates of proportions of recurrence free patients differed between treatment groups (fig 2).

\section{Mean duration of recurrences}

During both the observation and post-treatment periods, there were no differences between the treatment groups with respect to the mean duration of recurrences (table 3 ). However, during treatment, the mean duration for the acyclovir group (6.4 days) was significantly shorter $(p<0.05)$, than for the isoprinosine group ( $8 \cdot 2$ days).

\section{Mean duration of symptoms/erythema}

The mean duration of symptoms/erythema (that is, the total number of days per patient, with symptoms and/or erythema, but without lesions) was calculated for each treatment group. The $95 \%$ confidence intervals for differences between the means included zero and gave no evidence for any statistically significant differences between any pairs of treatment during the treatment or follow-up periods.

\section{Adverse events}

In general, all treatments were extremely well tolerated with only six patients reporting 11 adverse events, six in the acyclovir group (in three patients), four in the isoprinosine group (in two patients) and one in the placebo group. These were invariably mild, self-limiting, and of doubtful attributability to drug therapy. 


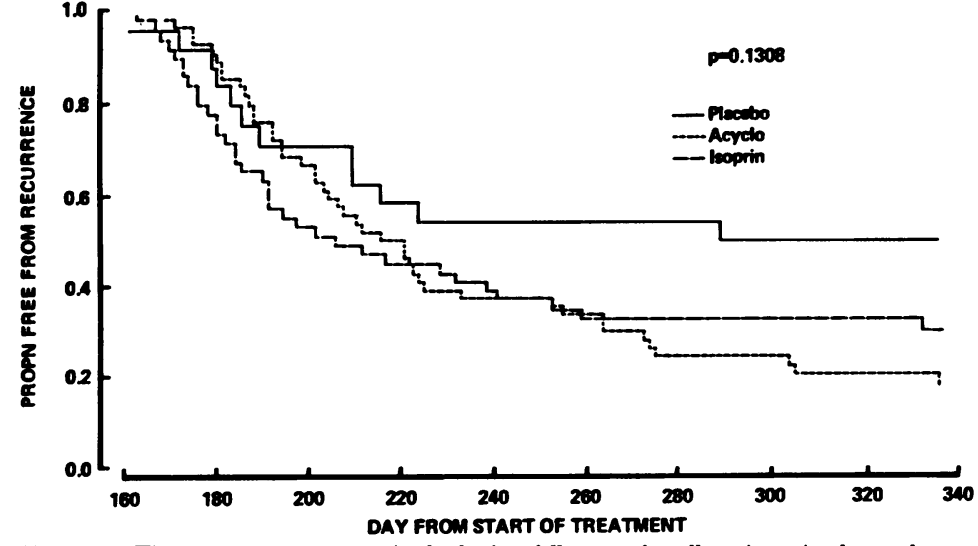

Figure 2 Time to 1st recurrent episode during follow-up for all patients in the study.

\section{Clinical laboratory evaluations}

The majority of patients did not suffer abnormal biochemical or haematological changes. The few detected abnormal values were generally lower than the expected values, these were mild, sporadic, did not follow a particular pattern and usually returned to normal.

\section{Discussion}

The results of this study are similar to those of previous placebo controlled trials ${ }^{3-7}$ which have confirmed the efficacy of acyclovir in suppressing recurrent genital herpes. Isoprinosine (Immunovir), an immunomodulator with low toxicity, has in some studies been shown to reduce the severity and speed of resolution of mucocutaneous herpes simplex reactivations. ${ }^{12-17}$ Although it has been claimed to reduce the duration of viral shedding and time to healing in patients with primary genital herpes, a recent comparative study showed that acyclovir treated patients had a shorter duration of symptoms and viral shedding, and healed more quickly than those treated with isoprinosine. ${ }^{18}$ However, neither preparation appeared to have any effect on the time to first recurrence or the frequency of subsequent recurrences.

The efficacy of a high dose isoprinosine regimen ( $1 \mathrm{~g}$ four times daily) has also been compared with acyclovir $800 \mathrm{mg}$ daily for the suppression of frequently recurring genital herpes. ${ }^{19}$ In this trial, $100 \%$ of patients receiving isoprinosine experienced recurrences compared with only $36 \%$ of those receiving acyclovir experienced recurrences during treatment.

The results of the present study, using a lower comparative dose of isoprinosine, are similar. Acyclovir treated patients experienced a significantly lower mean number of reported recurrences during treatment and significantly longer mean times to first recurrence as compared to those receiving isoprinosine or placebo. When breakthrough recurrences during treatment occurred, acyclovir treated patients had a significantly shorter mean duration of clinically diagnosed lesions than those treated with isoprinosine. Thus, treatment with acyclovir was markedly superior to treatment with isoprinosine which did not show any demonstrable advantages over placebo treatment. All treatments were well tolerated with no evi- dence of clinically significant effects on haematological and biochemical parameters.

The Kaplan-Meier curves for time to first recurrence in the post-treatment period were not significantly different among treatment groups. However, a significantly higher proportion of patients who had received acyclovir suffered recurrences during follow up compared with those treated with placebo but not isoprinosine. Whilst the number of recurrences in the acyclovir treatment group during follow up was greater than in the placebo treatment group, the frequency of recurrences in the placebo group decreased from the observation to the treatment period, and again from the treatment to the follow up period. This lower than expected rate in the placebo group in both the treatment and follow up periods (perhaps due to small patient numbers and/or too short an observation period), confounds the results somewhat. Nevertheless, recent results (Batenhorst et al, personal communication) have suggested that in patients receiving oral acyclovir for suppression of recurrent genital herpes infection for periods of 4 years, when treatment is terminated, the time to first recurrence is considerably longer than for patients who received shorter courses of therapy.

The results of this study demonstrate that acyclovir therapy is substantially more effective than isoprinosine therapy for the suppression of recurrent genital herpes. Similar results indicating the superiority of acyclovir for suppression of recurrent attacks have now been shown for studies of both low (1 $\mathrm{g})$ and high $(4 \mathrm{~g})$ daily doses of isoprinosine. Acyclovir is clearly the treatment of choice for the management of patients with both first episode and recurrent genital herpes. In the latter, the choice between episodic treatment with selfinitiated short treatment courses of oral acyclovir $^{20-22}$ or topical $5 \%$ acyclovir cream, ${ }^{2324}$ (both of which are of proven clinical efficacy) and continuous oral suppression, will depend upon individual patient assessment not only of their frequency of episodes but also the other physical, psychological and social effects of their recurrent disease.

The authors gratefully acknowledge the participation of the following: Dr J Nabarro, Central Middlesex Hospital, London, UK; Dr O Arya, Royal Liverpool Hospital, Liverpool, UK; Dr D C McDonald-Burns, Royal Free Hospital, London, UK; Dr J
Morias, Brussels, Belgium; Dr D Parent and Dr Lenniguin, Morias, Brussels, Belgium; Dr D Parent and Dr Lenniguin,
Erasme, Brussels, Belgium; Prof Ch. Lapierre and Dr Gexeau, Erasme, Brussels, Belgium; Prof Ch. Lapierre and Dr Gexeau,
Baviere-Dernmatologie, Liege, Belgium; Prof E Van Hecke and Prof Kint, Klinik Voos Hurdziekten, Ghent, Belgium.

We also acknowlege the support of The Department of Clinical Statistics and Data Handling, Wellcome Research Laboratories, Beckenham, Kent, UK.

1 Belsey EM, Adler MW. Current approaches to the diagnosis of herpes geni

2 Corey L, Holmes KK, Benedetti J, Critchlow C. Clinical course of genital herpes. Implications for therapeutic trials. In: Nahmias AJ, Dowdle WR, Schinazi RF, eds. The Human Herpes Virus. New York: Elsevier, 1981: 496-502.

3 Douglas JM, Critchlow C, Benedetti J, et al. A double blind study of oral acyclovir for suppression of recurrence of virus infection. $N$ Engl $\mathcal{f} M$ 1984;310:155-6.

4 Straus SE, Takiff HE, Seidlin M, et al. Suppression of frequently recurring genital herpes. A placebo controlled double blind trial of oral acyclovir. $N$ Engl $f$ Med 1984;310:1545-50. 
5 Mindel A, Weller IVD, Faherty A, et al. Prophylactic oral acyclovir in recurrent genital herpes. Lancet 1984;ii: 57-9.

6 Mindel A, Faherty A, Carney O, Patou G, Freris M, Williams P. Dosage and safety of long term suppressive acyclovir therapy for recurrent genital herpes. Lancet 1988;i:926-8.

7 Kinghorn GR, Jeavons $M$, Rowlands $M$, et al. Acyclovir prophylaxis of recurrent genital herpes: a randomised placebo controlled crossover study. Genitourin Med 1985;61:387-90.

8 Halsos AM, Salo OP, Lassus A, et al. Oral acyclovir suppression of recurrent genital herpes: a double blind placebo controlled crossover study. Acta Derm Venerol [Stockh] 1985;65:59-63.

9 Salo OP, Lassus A. Treatment of recurrent genital herpes with isoprinosine. Eur 7 Sex Transm Dis 1983;i:101-5.

10 Galli M, Lazzarin A, Moroni M, Zanussi C. Inosiplex in recurrent herpes simplex infections. Lancet 1982;ii: $331-2$.

11 Editorial. Immunovir tested in genital herpes and AIDS. Pharmaceutical fournal 1984;233:385.

12 Editorial. Inosine pranobex and mucocutaneous herpes. Lancet 1985; i:200-1.

13 Corey L, Chiang WT, Reeves WC, Starum WE, Brewer L Holmes KK. Effect of isoprinosine on the cellular immune response in initial genital herpes infection. Clin Res 1979;27:41A.

14 Talbot DJ, Menday AP. Inosine pranobex and mucocutaneous herpes. Lancet $1985 ; \mathbf{i}: 877$.
15 Galli M, Lazzarin A, Moroni M, Zanussi C. Inosiplex in recurrent herpes simplex infection. Lancet 1982;ii: 331-2.

16 Salo O, Lassus A. Treatment of recurrent genital herpes with isoprinosine. Eur $\mathcal{Y}$ Sex Transm Dis 1983;1:101-5.

17 Bouffat $\mathrm{P}$, Saurat JH. Isoprinosine as a therapeutic agent in recurrent mucocutaneous infections due to herpes virus recurrent mucocutaneous infections due to

18 Mindel A, Kinghorn GR, Allason-Jones E, et al. Treatment of first attack genital herpes: acyclovir versus inosine pranobex. Lancet 1987;i:1171-3.

19 Mindel A, Carney O, Sonnex C, et al. Suppression of frequently recurring genital herpes: acyclovir $\mathrm{v}$ inosine pranobex. Genitourin Med 1989;65:103-5.

20 Nilsen AE, Assen T, Halsos AM, Kinge BR, Tjotta EAL, et al. Efficacy of oral acyclovir in the treatment of initial and recurrent genital herpes. Lancet 1982;ii:571-3.

21 Salo OP, Lassus A, Hovi T. Double-blind placebo-controlled trial of oral acyclovir in recurrent genital herpes. Eur $\widetilde{J}$ Sex Transm Dis 1983;1:95-8.

22 Reichman RC, Badger GJ, Mertz GJ, et al. Treatment of recurrent genital herpes simplex infections with oral recurrent genital herpes simplex

23 Fiddian AP, Kinghorn GR, Goldmeier D, et al. Topical acyclovir in the treatment of genital herpes: a comparison with systemic therapy. $\mathcal{f}$ Antimicrob Chemother 1983;12 (Suppl B):67-77

24 Kinghorn GR. Topical acyclovir cream in the treatment of recurrent herpes simplex virus infections. Scand $\mathcal{f}$ Infect Dis $1985 ; 47$ (Suppl):58-62. 